\title{
Sobre armadilhas e cascas de banana: uma análise crítica da administração de Justiça em temas associados aos Direitos Humanos*
}

\author{
Marina Pereira Pires de Oliveira***
}

\begin{abstract}
Resumo
Com base no inteiro teor de sentenças condenatórias de tráfico de pessoas no Brasil, concedidas entre 2003 e o início de 2008, com base nos artigos 231 e 231-A do Código Penal, o artigo analisa o tratamento dado pelo Sistema de Justiça ao tema. A análise busca comparar o conceito internacional, consagrado na definição dada pelo Protocolo Adicional à Convenção das Nações Unidas contra o Crime Organizado Transnacional relativo à Prevenção, Repressão e Punição do Tráfico de Pessoas, em especial Mulheres e crianças, mais conhecido como Protocolo de Palermo, à idéia contida na normativa nacional. O objetivo maior da análise é buscar responder se é possível transformar grandes temas de Direitos Humanos em políticas públicas que efetivamente respondam aos interesses daqueles que pretendem proteger.
\end{abstract}

Palavras-chave: Direitos Humanos, Tráfico de Pessoas, Prostituição, Justiça, Protocolo de Palermo.

\footnotetext{
" Recebido para publicação em agosto de 2008, aceito em setembro de 2008.

** Formada em Comunicação Social (Jornalismo), coordenadora das ações de enfrentamento ao tráfico de pessoas da Secretaria Nacional de Justiça, do Ministério da Justiça, entre março de 2004 e março de 2007. marinappires@uol.com.br
} 
Sobre armadilhas e cascas de banana

About Traps and Other Slippery Questions:

A Critical Analysis of the Administration of Justice in Themes of Human

Rights

\begin{abstract}
Based on the full text of condemnatory sentences for human trafficking, issued by Brazilian courts between 2003 and the beginning of 2008, for articles 231 and 231-A of the national Penal Code, the article analyzes how the theme is seen by the Justice System. The analysis strives to compare the international concept contained in the definition of the United Nations Additional Protocol to the Convention Against Transnational Organized Crime to Prevent, Supress and Punish Human Trafficking, specially of women and children, better known as the Palermo Protocol, with the ideas contained in the national law. The greater objective of the analysis is to answer if it is possible to transform great themes of Human Rights into public policy that effectively responds to the interest of those groups they aim to protect.
\end{abstract}

Key Words: Human Rights, Human Trafficking, Prostitution, Justice, Palermo Protocol. 
Marina Pereira Pires de Oliveira

\section{Apresentação}

O presente artigo parte da leitura crítica de sentenças condenatórias e absolutórias concedidas, em primeira instância, referentes aos artigos 231 e 231-A do Código Penal Brasileiro, tráfico internacional de pessoas e tráfico interno de pessoas ${ }^{1}$, respectivamente, concedidas entre janeiro de 2003 e fevereiro de 2008 por tribunais federais e estaduais brasileiros. Foram analisadas 14 sentenças condenatórias e duas absolutórias que representam a totalidade de casos localizados pela autora, como parte de uma pesquisa global do Escritório das Nações Unidas contra Drogas e Crime (UNODC), sobre a resposta dada pelos diversos países ao tema do tráfico de pessoas em três áreas: a) adaptação do marco normativo nacional ao Protocolo Adicional à Convenção das Nações Unidas contra o Crime Organizado Transnacional relativo à Prevenção, Repressão e Punição do Tráfico de Pessoas, em especial Mulheres e crianças, mais conhecido como Protocolo de Palermo; b) Sistema de Justiça Criminal e c) Atenção às vítimas. A pesquisa foi realizada na América do Sul (Argentina, Brasil, Chile, Paraguai, Bolívia, Peru, Colômbia e Equador) entre agosto de 2007 e maio de 2008.

Os documentos foram localizados usando metodologias diferentes com o objetivo de reunir o maior número possível de sentenças sobre o tema no país. Não existe um banco de dados integrado do Poder Judiciário que permita produzir um relatório nacional sobre os casos de 231 e 231-A sob análise dos juízes.

Primeiro, foram usadas as informações disponíveis no banco de dados da Polícia Federal, instituição com competência para

\footnotetext{
${ }^{1}$ Art.231 - Promover, intermediar ou facilitar a entrada, no território nacional, de pessoa que venha exercer a prostituição ou a saída de pessoa para exercê-la no estrangeiro; Art. 213-A - Promover, intermediar ou facilitar, no território nacional, o recrutamento, o transporte, a transferência, o alojamento ou o acolhimento da pessoa que venha exercer a prostituição (redação dada pela lei $11.106,28 / 03 / 2005)$
} 
Sobre armadilhas e cascas de banana

investigar o tráfico internacional de pessoas. A cada inquérito corresponde um número de processo aberto na Justiça. De posse dos números de processos gerados por inquéritos da PF, iniciados entre 2003 e 2007, foi possível rastrear, via Internet e em contatos telefônicos, a existência ou não de decisão judicial sobre os casos.

A parceria com a Organização Internacional do Trabalho (OIT), a Secretaria Especial de Direitos Humanos da Presidência da República (SEDH) e o Comitê Nacional de Enfrentamento à Violência Sexual contra Crianças e Adolescentes possibilitou a ampliação da pesquisa. A colaboração dessas instituições - que fizeram uma consulta formal a todas as comarcas e tribunais de Justiça dos estados pedindo que fossem informados os processos referentes ao tipo penal 231 e 231-A em andamento - contribuiu para a elaboração de uma lista mais ampla que abrangia a ação das polícias civis, bem como decisões proferidas pelos tribunais estaduais.

É importante salientar que o referido levantamento ${ }^{2}$ não foi publicado e, devido ao formato do instrumental de pesquisa adotado, só foram incluídos no relatório global o número de sentenças dadas e o número de pessoas condenadas pela Justiça. Dessa forma, as análises contidas neste artigo são inéditas e de total responsabilidade da autora, não refletindo o posicionamento do UNODC.

2 Os dados enviados pelos estados e consolidados pela OIT/SEDH/Comitê Nacional, como parte de um estudo a ser lançado ainda em 2008, permitiram verificar, via telefone e internet, se tais processos haviam gerado alguma decisão judicial. Depois de chegar aos números de processos nos quais houve condenação ou absolvição pelos tipos 231 ou 231-A, foram enviados ofícios aos tribunais pedindo cópia do inteiro teor das sentenças. Nesse esforço de pesquisa foram localizadas ainda outras sentenças de segunda instância ou de tribunais superiores. Esse material, entretanto, não foi utilizado nessa análise e nem tampouco no relatório global do UNODC. A decisão se justifica pelo fato da leitura tanto deste artigo quanto da pesquisa do UNODC não ter caráter jurídico, mas focada na resposta dada pelo Estado ao tema, numa ótica das políticas públicas. 
O inteiro teor das sentenças mencionadas, complementadas por entrevistas realizadas ao longo do trabalho, num esforço de compreensão e leitura dos dados quantitativos coletados, serviram de base para analisar dois aspectos relacionados com a administração de Justiça em casos de tráfico de pessoas no Brasil. Primeiro, abordo como a associação direta entre prostituição $e$ tráfico de pessoas orienta o trabalho do Sistema de Justiça muito mais para o combate à prostituição do que para o problema delimitado como tráfico de pessoas pelas convenções internacionais.

Em seguida, levando em conta minha experiência como coordenadora do enfrentamento ao tráfico de pessoas da Secretaria Nacional de Justiça do Ministério da Justiça, entre 2004 e o início de 2007, trato da dificuldade concreta das políticas públicas em ampliar a visão da sociedade, particularmente dos operadores de Direito, sobre o tema. Essa reflexão tenta responder se é possível transformar grandes temas de Direitos Humanos, como é o caso do tráfico de pessoas, em ações concretas e reais que sirvam às possíveis vítimas. Em alguns momentos, faço uma comparação com os demais países da América do Sul, aproveitando a experiência acumulada ao longo da pesquisa do UNODC.

A leitura crítica das sentenças condenatórias e absolutórias referentes aos artigos 231 e 231-A mostra o quanto a associação direta entre tráfico e prostituição condena o Estado a uma ação desarticulada, lenta e, por vezes, contraditória, dificultando o estabelecimento de uma política pública efetiva de proteção aos direitos das vítimas.

Do ponto de vista de quem sofreu a violação, a ação do Sistema de Justiça não representa reparação do dano sofrido $e$, muitas vezes, ao contrário, mina a estratégia de sobrevivência encontrada individualmente por essas mulheres que o Estado agiu para proteger. Neste artigo, argumento que uma saída para esse conjunto de problemas seria ampliar a noção de tráfico de pessoas, a exemplo do que foi feito na definição adotada pelo 
Sobre armadilhas e cascas de banana

Protocolo de Palermo, enfatizando o elemento da exploração por ele apresentado.

\section{Primeiras armadilhas}

O primeiro desafio na busca por Justiça em temas associados aos Direitos Humanos, como o tráfico de pessoas, reside em entender todos os ângulos pelos quais se pode enxergar o problema. O tráfico humano tem um forte componente de gênero, mas essa perspectiva sozinha não abarca todos os aspectos envolvidos. Muitas vezes, se apresenta como o estágio mais avançado de um longo processo de exclusão social, mas a pobreza sozinha também não o explica. Noutras ocasiões, o tráfico se confunde com questões relacionadas à desigualdade entre as nações $e$ aos processos migratórios modernos. Entretanto, enxergar os vários lados do problema sem perceber como eles se relacionam também não basta, porque, na vida real, todos os aspectos se manifestam de uma só vez, na mesma pessoa: a vítima do tráfico.

É no momento da identificação de uma vítima - seja pela polícia, seja por organizações não-governamentais ou públicas de assistência social e de saúde, entre outras - que a demanda concreta pela administração de Justiça se apresenta. Faz-se necessário abrir um parêntese para chamar a atenção para uma particularidade da atuação na área das Ciências Humanas, como é o caso do Direito. Quando nos deparamos profissionalmente com situações de prostituição, de violência e de migração, por exemplo, enxergamos o caso concreto diante de nós pelo prisma de nossa criação, de nossas experiências anteriores e de nossa visão política e ideológica, para dizer o mínimo. Em outras palavras, os valores compartilhados por certos setores da sociedade em relação aos sujeitos identificados como "vulneráveis ao tráfico de pessoas" determinam, em grande parte, o tratamento dado pelo Sistema de Justiça e pelas políticas públicas, de maneira geral, ao tema. Reconhecer essa particularidade é o 
Marina Pereira Pires de Oliveira

primeiro passo para levá-la em conta na tomada de decisões sobre políticas públicas em temas dessa natureza.

\section{Gênero e prostituição}

Diferentes atores sociais, desde a polícia até assistentes sociais e psicólogos, relatam dificuldade especial em abordar $e$ lidar com mulheres adultas vítimas do tráfico de pessoas.

Em geral as mulheres adultas e vítimas do tráfico de pessoas que chegam do exterior não querem nossa ajuda humanitária. Elas buscam voltar o mais cedo possível para o exterior e quando conseguimos levá-las a um abrigo ou uma estrutura desse tipo os problemas são muitos. Seja pela atitude agressiva que adota em relação aos demais no abrigo, seja pelas roupas provocantes que usa. Ela costuma despertar muito mais animosidade por parte dos outros abrigados $e$ dos próprios funcionários do que um sentimento de compaixão pela violação que sofreu (depoimento de coordenadora de organização não-governamental que trabalha com vítimas do tráfico de pessoas).

Existe uma série de razões para essa sensação de desconforto provocada pela vítima com esse perfil. Por um lado, a percepção hegemônica sobre o tráfico de pessoas dá lugar a uma resistência muito maior em aceitar uma mulher adulta do que uma criança ou adolescente como vítima desse crime. Nessa percepção hegemônica, uma menina pode ser forçada à prostituição, mas uma adulta escolhe esse caminho e, nesse pensamento, está implícito algum desvio moral ou ético por parte da mulher. Isso ocorre principalmente pela tendência em misturar tráfico de pessoas com a discussão, os conceitos e os pré-conceitos sobre a prostituição (Anderson \& O'Connel, 2004).

Dois fatores principais geram essa dificuldade, resultando em uma grande barreira para o agendamento do debate sobre tráfico de mulheres adultas não somente no Brasil, mas na maior 
Sobre armadilhas e cascas de banana

parte dos países da América do Sul. Primeiro, existe uma divergência no movimento feminista mundial com relação à prostituição. Parte das ativistas dos direitos da mulher enxerga nessa atividade uma violação histórica, uma forma de dominação sistemática, fazendo com que atribuam à prostituição uma carga moral negativa pela submissão que representaria (Piscitelli, 2006a).

Alguns setores da sociedade, por razões diferentes das feministas, também atribuem a essa atividade uma carga moral negativa, culpando a prostituta por uma série de "problemas sociais" - entre outros, a destruição das famílias, as doenças sexualmente transmissiveis -, responsabilizando-as diretamente pelos abusos físicos ou psicológicos eventualmente sofridos (Fonseca, 1996).

Dois olhares sobre uma mesma questão exigem da mulher adulta inserida na prostituição uma determinada postura para que seja considerada como beneficiária de uma ação de enfrentamento ao tráfico de pessoas (Barry, 1997). Espera-se da "verdadeira vítima" o relato e os trejeitos de alguém enganado ou levado por uma série de vulnerabilidades ao mercado do sexo, condenado como moralmente degradante, mesmo a partir de perspectivas completamente diferenciadas. Espera-se, ainda, uma condenação tácita do comércio do corpo e um manifesto desejo de ganhar a vida de outra forma.

De alguma maneira, como gestores de políticas públicas, precisamos torcer os fatos para tornar o tráfico de mulheres adultas para fins de prostituição uma bandeira minimamente palatável aos padrões morais hegemônicos da sociedade.

Diante de jornalistas, de uma platéia de policiais ou de estudantes, e mesmo em reuniões com gestores de outros órgãos do governo federal ou estadual, ume recorrente a ansiedade dos interlocutores de ter certeza de que a vítima da qual falávamos havia sido enganada ou de alguma maneira "forçada" à situação de prostituição. Por uma série de razões que serão destrinchadas ao longo desse artigo, era difícil, e continua sendo, fazer ver que uma prostituta, como qualquer outro cidadão, pode ter seus 
direitos violados. Mais ainda, mostrar que o elemento central do tráfico não é a prostituição, embora prostitutas também possam ser vítimas desse crime, mas a violação de direitos sofrida por um trabalhador doméstico, rural ou do sexo, por que não?! Declarações desse tipo não costumam ser bem-recebidas pela moral hegemônica da sociedade e tampouco ajudam a angariar aliados para essa bandeira. Mas essa é mais uma das muitas armadilhas do tema.

\section{Teoria e prática}

Nos casos concretos de tráfico de pessoas enquadrados na definição do Código Penal Brasileiro (artigos 231 e 231-A), a vítima diante do policial, do promotor e do juiz afirma, na maioria das vezes, não ter sido enganada, tampouco forçada à prostituição. Tal situação, freqüente nas investigações e processos referentes a esse crime, deixa o profissional do sistema de Justiça e da área de atendimento perplexos, sem saber como agir com relação a essa pessoa real, que, na maioria das vezes, não guarda nenhuma similaridade com o imaginário coletivo de uma vítima, menos ainda de uma vítima adulta com histórico de prostituição.

$\mathrm{O}$ desconforto provocado pela mulher adulta enquadrada como vítima do tráfico de pessoas pela definição do Código Penal, muitas vezes, tem origem numa expectativa dos agentes do Estado de uma condenação da prostituição como meio de vida pela mulher supostamente "salva" pela intervenção das instituições. Estudos sobre o tema mostram que, na prática, grande parte dessas mulheres identifica a ação do Estado como uma atrapalhação, um atraso de vida (Agustín, 2007). Outras demonstram orgulho por terem encontrado estratégias próprias de sobrevivência que viabilizaram a obtenção de uma casa própria ou a criação dos filhos, por exemplo, diante da absoluta falta de mobilidade social encontrada pela maioria das mulheres com seu perfil em suas comunidades originais. 
Sobre armadilhas e cascas de banana

Ao estigma social da atividade sexual soma-se a armadilha criada por tipos penais, os artigos 231 e 231-A, voltados muito mais para a persecução de redes de facilitação da prostituição do que de grupos criminosos que exploram e violam sistematicamente os Direitos Humanos - foco da definição de Palermo.

Nesse ponto, vale confrontar o tipo penal vigente segundo redação dada pela lei 11.106 de 28/03/05 e o artigo $3^{\circ}$ do Protocolo de Palermo. Diz o Código Penal:

\section{Tráfico Internacional de Pessoas}

Art. 231. Promover, intermediar ou facilitar a entrada, no território nacional, de pessoa que venha exercer a prostituição ou a saída de pessoa para exercê-la no estrangeiro.

\section{Tráfico Interno de Pessoas}

Art. 231-A. Promover, intermediar ou facilitar, no território nacional, o recrutamento, o transporte, a transferência, o alojamento ou o acolhimento da pessoa que venha exercer a prostituição:

\section{Diz o Protocolo de Palermo:}

Artigo 3o: O tráfico de pessoas é o recrutamento, o transporte, a transferência, o alojamento ou o acolhimento de pessoas, recorrendo à ameaça ou uso de força ou a outras formas de coação, ao rapto, à fraude, ao engano, ao abuso de autoridade ou à situação de vulnerabilidade ou à entrega ou aceitação de pagamentos ou benefícios para obter consentimento de uma pessoa que tenha autoridade sobre outra, para fins de exploração. A exploração inclui, no mínimo, a exploração da prostituição de outrem ou outras formas de exploração sexual, os trabalhos ou serviços forçados, escravatura ou práticas similares à escravatura, a servidão ou a remoção de órgãos. 
A definição do Código Penal restringe a finalidade da exploração à prostituição e, ao mesmo tempo, elimina o debate sobre o consentimento ou não da vítima, incorporado pelo texto de Palermo. Dessa forma, na aplicação dos tipos penais específicos, torna-se muito difícil separar a migração interna ou internacional para fins de prostituição do tráfico de pessoas (Piscitelli, 2006b).

Entre a pessoa real diante de si, o conceito de Palermo e as ferramentas oferecidas pelo Código Penal, o policial encontra-se diante de uma situação confusa e, por vezes, contraditória. Participei de diversas iniciativas de capacitação para policiais sobre o tema do tráfico de pessoas no período em que estive no Ministério da Justiça e, mais tarde, no UNODC. Depois de fazer qualquer explanação sobre o marco do tema dado pela convenção internacional e explicar os elementos definidores do tráfico, recebia sempre a mesma pergunta: como é possível aplicar esse conceito internacional se o Código Penal define de outra maneira esse crime?

Como não cabe ao policial mudar as leis, tampouco articular a rede de retaguarda psicossocial necessária para um atendimento diferenciado à suposta vítima, ele opta por investigar o crime dentro das possibilidades oferecidas pelo Código Penal. Tenta conseguir alguma condenação para os autores, sem, todavia, prestar qualquer tipo de assistência psicossocial às vítimas identificadas. Como pesquisadora, contratada para levantar informações sobre a resposta dos países sul-americanos ao tema do tráfico de pessoas, verifiquei empiricamente essa situação.

Existem dados, mesmo que esparsos, difíceis de consolidar $e$ pulverizados, sobre inquéritos e processos. Entretanto, ao entrevistar policiais e promotores de Justiça para tentar descobrir informações sobre as medidas de assistência e proteção aplicadas às vítimas identificadas nestes mesmos inquéritos e processos, a resposta era quase sempre a mesma: ninguém sabia o que havia acontecido com elas depois de prestarem depoimento. Outros afirmavam que, por se tratarem de vítimas adultas, nunca houve 
Sobre armadilhas e cascas de banana

qualquer tipo de encaminhamento à rede da assistência social ou da saúde, na maioria das vezes, pela absoluta falta de interesse demonstrada pelas próprias mulheres nesse tipo de medida.

A experiência da maior parte do nosso pessoal é de que não existe interesse por parte das vítimas em receber acompanhamento psicossocial. Muitas querem tentar voltar ao exterior em outras condições mais adiante. Além disso, o foco do policial está na condução do inquérito $e$, talvez por isso, essa preocupação com a vítima e com o seu encaminhamento a uma rede social não faça parte ainda da nossa cultura (Delegado, integrante da Divisão de Direitos Humanos da Policia Federal, dezembro de 2007).

No final, ficavam sempre as mesmas perguntas sem resposta: Afinal, essas mulheres adultas oficialmente identificadas como vítimas do tráfico, por estarem dentro de inquéritos $e$ processos com esse nome, são ou não vítimas? Em caso afirmativo, por que não conseguimos dar a elas a reparação que as convenções internacionais lhes garantem? Em caso negativo, se elas não são vítimas, então qual é o crime que o Estado está combatendo? A prostituição? Mas prostituição não é crime, embora também não seja legalizada no Brasil. Mais uma casca de banana no caminho do gestor público interessado em promover uma política pública efetiva nessa área.

A questão que se coloca é a seguinte: toda pessoa ou grupo de pessoas (mesmo que seja formado por conhecidos e parentes) agindo isoladamente ou em conjunto no sentido de facilitar o deslocamento de pessoas para inserção no mercado sexual pratica o tráfico de pessoas? Na prática, em países como o Brasil, onde o Código Penal contém definições, em seus tipos específicos (art. 231 e 231-A) que não incorporam as demais modalidades de exploração, além da sexual, parece que sim, embora a definição do Protocolo de Palermo aponte de forma inequívoca no sentido contrário. 
É importante lembrar que o Sistema de Justiça e Responsabilização (polícias, Ministério Público, Poder Judiciário) atua na esfera criminal sob a orientação do Código Penal. Portanto, ainda que existam operadores de Direito cujo entendimento do conceito de tráfico de pessoas tenha sido alargado pelo conhecimento do Protocolo de Palermo, a atuação cotidiana desses agentes está limitada pelo Código Penal. Nesse sentido, a redação atual do marco normativo nacional reforça a armadilha da associação direta entre o tráfico de pessoas e a prostituição. Mais do que isso, orienta o trabalho do Sistema de Justiça no sentido do enfrentamento à prostituição e não do problema delimitado como tráfico de pessoas pelas convenções internacionais. Essa argumentação precisa ser entendida $e$ considerada muito além do aspecto jurídico.

No Código Penal existem outros artigos que, de alguma maneira, abarcam as demais modalidades de exploração contidas no Protocolo de Palermo, entre outros, os artigos $149^{3}$ (Redução a condição análoga à de escravo), $206^{4}$ (Aliciamento para o fim de emigração), e $207^{5}$ (Aliciamento de trabalhadores de um local para

\footnotetext{
${ }^{3}$ Redução a condição análoga à de escravo (Art. 149). Reduzir alguém a condição análoga à de escravo, quer submetendo-o a trabalhos forçados ou a jornada exaustiva, quer sujeitando-o a condições degradantes de trabalho, quer restringindo, por qualquer meio, sua locomoção em razão de dívida contraída com o empregador ou preposto.

$\S 1$ o Nas mesmas penas incorre quem:

I - cerceia o uso de qualquer meio de transporte por parte do trabalhador, com o fim de retê-lo no local de trabalho;

II - mantém vigilância ostensiva no local de trabalho ou se apodera de documentos ou objetos pessoais do trabalhador, com o fim de retê-lo no local de trabalho (redação dada pela lei 10.803 de 11/12/2003).
}

4 Aliciamento para o fim de emigração (Art. 206) - Recrutar trabalhadores, mediante fraude, com o fim de levá-los para território estrangeiro (redação dada pela lei 8.683, de 1993).

${ }^{5}$ Aliciamento de trabalhadores de um local para outro do território nacional (Art. 207) - Aliciar trabalhadores, com o fim de levá-los de uma para outra localidade do território nacional: 
Sobre armadilhas e cascas de banana

o outro do território nacional). Portanto, do ponto de vista estritamente jurídico, os operadores de Justiça podem aplicar diferentes partes da lei para coibir o tráfico de pessoas, mesmo que o enquadramento penal leve outro nome devido à deficiência do tipo específico. Isso sem mencionar o fato de que as penas aplicadas a outros tipos existentes relacionados com o tráfico de pessoas são extremamente leves.

Mas a leitura crítica do inteiro teor das 14 sentenças condenatórias e 2 absolutórias proferidas pelos tribunais federais e estaduais brasileiros, em primeira instância, entre janeiro de 2003 e fevereiro de 2008, evidencia o resultado prático produzido por essa inadequação do tipo penal atual. As sentenças são resultado de situações ocorridas entre 1999 e 2006.

\section{Tráfico e prostituição}

Percebem-se, nessas sentenças, duas respostas diferenciadas do Sistema de Justiça ao tema, nenhuma delas voltada para a promoção dos Direitos Humanos das vítimas. O primeiro grupo de condenações, no qual se concentra a maior parte das sentenças encontradas, atinge claramente organizações ou indivíduos que atuam para facilitar a prostituição de terceiros, seja no Brasil, seja no exterior. Em outras palavras, os elementos definidores do tráfico que são: a violência ou o uso da força ou abuso de situação de vulnerabilidade no processo de aliciamento, bem como a exploração a qual a vítima foi submetida, seja na indústria do sexo, no serviço doméstico, na plantação de cana, etc., sequer aparecem na maior parte dos casos. Nesse grupo de sentenças, inclusive, tais elementos estão pouco presentes nos depoimentos.

$\$ 1^{\circ}$ Incorre na mesma pena quem recrutar trabalhadores fora da localidade de execução do trabalho, dentro do território nacional, mediante fraude ou cobrança de qualquer quantia do trabalhador, ou, ainda, não assegurar condições do seu retorno ao local de origem (redação dada pela lei 9.777, de 29/12/1998). 
Marina Pereira Pires de Oliveira

Em decisão proferida pela Justiça Federal da Bahia (processo 2006.33.00.005669-9), escolhida para a citação por exemplificar bem esse grupo de sentenças, uma das vítimas do processo declara:

(...) que $\mathrm{CO}$ disse para a depoente, explicitamente, que o lugar para onde seria enviada, na Espanha, era uma casa de prostituição (...) que a depoente chegou a receber telefonemas de uma mulher, de nome LA, que mora na Espanha e com quem iria trabalhar, juntamente com $\mathrm{EA}$, que sabia que estava indo para a Espanha se prostituir, (...) que AN recepcionou a depoente e sua amigas, hospedando as duas em seu apartamento, que AN tinha conhecimento de que a depoente e sua amiga estavam embarcando para a Espanha, a fim de trabalhar em casa de prostituição, mas afirmou que ele, AN só tratava com as passagens.

Mais adiante, ao condenar o réu pelo crime previsto no art. 231, em sua forma tentada, uma vez que o embarque das vítimas foi impedido pela ação da Polícia Federal, o juiz escreve:

Os documentos colhidos não deixam dúvidas que AN era, de fato, encarregado pelo encaminhamento de pessoas para o exterior, tanto que, em um lapso temporal de poucos 5 (meses), adquiriu trinta e cinco bilhetes aéreos para a Europa (...) a sua conduta se amolda ao tipo descrito no art. 231 do Código Penal Brasileiro.... Indaga-se: todos os demais embarques de pessoas para o exterior [feitos por AN] se amoldam, perfeitamente, ao tipo do art. 231 do CP? Entendo que tal afirmação não possa ser explicitada, já que a limitação probatória imposta pelo tempo, não permitiu a localização de qualquer das demais pessoas mencionadas... ou que diligências empreendidas pela INTERPOL pudessem ser consumadas para averiguar as atividades desenvolvidas por tais pessoas no estrangeiro. 
Sobre armadilhas e cascas de banana

Os trechos explicitam a inexistência de qualquer preocupação com a eventual exploração sofrida pelas vítimas. O foco está claramente no ato praticado pelo réu de ajudar mulheres adultas a saírem do país para praticarem a prostituição.

Em parte, isso se explica porque o conceito de exploração não integra o tipo penal. A natureza do nosso Direito é o de exigir uma relação perfeita entre a descrição feita na lei e o fato sob escrutínio. Quanto mais próximo da definição contida na lei estiver a situação sob análise, mais provável a condenação. Por isso, explorar esses elementos que estão na base da definição internacional do tráfico de pessoas, mas não entram no Código Penal, significa um desperdício de energia durante o processo de investigação e persecução criminal.

Outro ponto digno de nota é o fato da maior parte das pessoas acusadas nesses processos ser do sexo feminino, 39 de um total de 70 pessoas. Uma explicação possivel é que a redação dos tipos penais atuais, voltados para a criminalização da facilitação da prostituição e não para o combate ao crime organizado, orienta a ação do Sistema de Justiça na direção da punição de pessoas mais próximas da vítima, que costumam auxiliá-la no processo de saída do país para inserção no mercado do sexo.

A sentença proferida pela Justiça Federal em Uberlândia (2004.38.03.009474-5) exemplifica bem o perfil de algumas das condenadas nos documentos coletados. A ré em questão estaria ajudando mulheres da região de Uberlândia (MG) a viajar para a Suíça para fins de prostituição. O trecho abaixo evidencia a existência de um relacionamento pessoal entre as vítimas e a acusada:

depoimento da testemunha arrolada pela própria defesa, EI, conhecedora das condições sociais e econômicas das vítimas, oportunidade em que alegou: ...que a depoente acredita que a amizade entre LA, AA e RE não era ao ponto 
Marina Pereira Pires de Oliveira

de LA pagar as passagens para o exterior "elas não teriam condições de pagar depois".

A própria vítima, em seu depoimento, afirma:

(...) QUE, sempre morou em Tupaciguara/MG e por necessidade financeira tão logo completou dezoito anos de idade, passou a se prostituir; ...QUE, há dois meses aproximadamente foi até a casa de LA para saber da mesma a possibilidade de que viesse lhe orientar e até mesmo viabilizar sua ida para a Suíça; QUE, não dispunha de dinheiro para a passagem $e$ para aquisição de passaporte; QUE, após conversar com LA e esta lhe orientar que o trabalho a ser desenvolvido seria de prostituição, acordaram então que a mesma adquirisse os bilhetes de passagens para Paris; QUE, combinaram ainda na ocasião, que a depoente deveria pagar-lhe US $\$ 12.000,00$ (DOZE MIL DÓLARES) ao longo do tempo em que permanecesse se prostituindo naquele país, e tão logo quitasse o débito, todo o dinheiro auferido com a prostituição lhe pertenceria; QUE, estava muito animada com a possibilidade de ganhar dinheiro e poder ajudar sua família, daí aceitar pagar um valor tão alto como o estabelecido por LA; QUE, a LA orientou a depoente $e$ sua amiga AA que assim que desembarcassem em Paris deveriam pegar um trem até a cidade de Laussane/Suíça onde alguém as esperariam para levar até o apartamento onde iriam morar; QUE, também lhe fora dito que por cada "programa" que fizesse ganharia o equivalente a $\mathrm{R} \$ 200,00$ (DUZENTOS REAIS); QUE, hoje após tudo acertado, a Luzia trouxe a depoente e sua amiga AA até o aeroporto da cidade, de onde embarcariam com destino a Paris (...).

$\mathrm{O}$ fato de o embarque ter sido impedido pela Polícia Federal, que já investigava a ré e a ausência de outros elementos que apontassem para situação de exploração no destino, acaba por deixar o leitor orientado pela definição do Protocolo de Palermo, colocando em dúvida a existência ou não de uma 
Sobre armadilhas e cascas de banana

situação de tráfico de pessoas à luz das convenções internacionais, embora seja clara a relação entre o tipo penal e a situação analisada.

O segundo grupo de sentenças, todas elas posteriores a 2005 , resulta de um trabalho mais longo de inteligência policial $e$ articula a investigação sobre o tráfico de pessoas com questões de crime organizado transnacional, como a lavagem de dinheiro e a formação de quadrilha. Entretanto, mais uma vez, os elementos definidores do tráfico, sobretudo a exploração, continuam fora do foco do trabalho do Sistema de Justiça Criminal.

Nas sentenças referentes ao tráfico interno (231-A), criado em 2005, a situação torna-se ainda mais confusa. Nas sentenças analisadas, não é possível entender o que diferencia as situações reais enquadradas como tráfico interno de casos de exploração sexual pura e simples - casos cobertos pelos artigos $228^{6}$ (favorecimento da prostituição), $229^{7}$ (casa de prostituição) ou $230^{8}$ (rufianismo) do Código Penal. É importante salientar que não se trata de discutir a doutrina do Direito Penal, mas de entender em que situações concretas ele tem sido aplicado, no sentido de olhar para o impacto da administração de Justiça na vida real da população.

Os casos de 231-A encontrados parecem resultar de flagrantes de delito feitos pela polícia nos estados, diante de denúncia da ocorrência de exploração sexual comercial de crianças $e$ adolescentes em casas noturnas. Ao que parece, quando as investigações comprovam a presença de menores de 18 anos nesses estabelecimentos, com a utilização do mesmo

\footnotetext{
${ }^{6}$ Favorecimento da prostituição (Art. 228) - Induzir ou atrair alguém à prostituição, facilitá-la ou impedir que alguém a abandone:

7 Casa de prostituição (Art. 229) - Manter, por conta própria ou de terceiro, casa de prostituição ou lugar destinado a encontros para fim libidinoso, haja, ou não, intuito de lucro ou mediação direta do proprietário ou gerente:

8 Rufianismo (Art. 230) - Tirar proveito da prostituição alheia, participando diretamente de seus lucros ou fazendo-se sustentar, no todo ou em parte, por quem a exerça.
} 
espaço como moradia das meninas ou meninos, ocorre o enquadramento no artigo 231-A. Outro ponto interessante é que o 231-A vem sempre aplicado em conjunto com os artigos 228,229 ou 230 , no caso de não se comprovar a existência de menores de idade no estabelecimento.

É importante ressaltar que não há, nesta análise, qualquer tipo de crítica ao fato de a polícia utilizar o artigo 231-A para coibir a exploração sexual de crianças e adolescentes. Ao contrário, todas as armas institucionais disponíveis devem ser utilizadas no enfrentamento desse problema. O questionamento é em relação à adequação do tipo penal como ferramenta para que os operadores de Direito possam efetivamente enfrentar o tráfico de pessoas tal qual definido pelo Protocolo de Palermo. Mais uma vez, fica clara a orientação do marco normativo atual para o combate à prostituição e não ao tráfico de pessoas, aumentando a confusão e a associação direta entre os dois temas.

Também é importante frisar que foram localizadas somente duas sentenças condenatórias e uma absolutória nesse tipo específico, compondo uma amostra extremamente restrita da realidade nacional. De qualquer maneira, o pouco tempo de existência do novo artigo (2005) permite inferir que as decisões encontradas estão entre as primeiras proferidas no país sobre tráfico interno e, portanto, são significativas para analisar a leitura que o Sistema de Justiça vem fazendo desse novo artigo.

Nas sentenças referentes ao 231-A, é possível perceber a ligação entre o fato de uma ou mais vítimas identificadas, independentemente de serem ou não menores de idade, terem vindo de outro município com a utilização desse tipo penal específico pela polícia.

A sentença proferida pelo Poder Judiciário do Estado do Paraná (22/06), da comarca de São João do Triunfo, mostra a leitura que tem sido feita pelos juízes do novo tipo penal.

Resta por demais evidenciado, que o acusado $\mathrm{CO}$ escolhia $e$ acolhia (alojava) as pessoas que vinham exercer a 
Sobre armadilhas e cascas de banana

prostituição, na casa por ele mantida, denominada "Boate Casarão" ...Além de manter uma casa destinada a prostituição, promovia o recrutamento (contato com as mulheres) e o alojamento das moças que vinham de outras cidades (seja de carona, seja trazidas por ele próprio) para exercer o comércio do corpo, no citado estabelecimento, onde, como visto alhures, existiam quartos no interior da casa destinados aos encontros carnais, que se davam com habitualidade. As prostitutas que trabalhavam na casa administrada pelo réu, ali ficavam alojadas e se alimentavam, sendo que, obviamente, recebiam pelos programas sexuais mantidos.

\section{O caso da Colômbia}

O exemplo da Colômbia demonstra a dificuldade de importar o conceito contido em Palermo para o nosso marco normativo nacional. A Colômbia, mesmo antes de ratificar o Protocolo, ainda em 2002, fez uma mudança em seu Código Penal e copiou a definição do artigo $3^{\circ}$ da convenção internacional para seu ordenamento jurídico interno. Com isso, o Sistema de Justiça daquele país começou a trabalhar com a idéia contida em Palermo de que somente na presença de coerção, fraude ou abuso de situação de vulnerabilidade é que o tráfico pode ocorrer.

Entretanto, após três anos de tentativa de aplicação dessa nova redação, eles descobriram que a complexidade da definição do Protocolo de Palermo é extremamente difícil de comprovar dentro da cultura jurídica dos países de origem ibérica. Isso porque a exigência de mostrar uma relação quase perfeita entre o tipo penal e o fato sob análise acaba por dificultar condenações em tipos penais de definição mais complexa, nos quais a comprovação da materialidade do crime é menos palpável. Um conceito que traz a exploração como elemento central, como é o caso de Palermo, requer uma definição comum do que seja exploração. 
Durante a pesquisa, ouvi relatos de estudiosos do tema e de operadores de Direito na Colômbia que afirmaram que havia uma preferência dos policiais por não utilizar o tipo penal de tráfico de pessoas modificado em 2002, pela dificuldade em conseguir sucesso nos tribunais. Os legisladores colombianos optaram, então, em 2005, por retirar a questão do consentimento da vítima, presente em Palermo, da nova redação dada ao tipo penal de tráfico de pessoas. Prevaleceu o entendimento de que a subjetividade do próprio conceito de consentimento dado pela vítima ADULTA, entenda-se bem, favorecia a absolvição dos autores. A percepção hegemônica da sociedade, refletida no Poder Judiciário, não conseguia aceitar a mulher adulta como vítima, sobretudo em casos de exploração sexual. Os legisladores também optaram por criar uma definição do termo exploração e incluí-la no Código Penal, logo abaixo do tipo de tráfico de pessoas.

O exemplo da Colômbia também é rico em outros aspectos. Em primeiro lugar porque, independentemente do tipo penal abarcar outras modalidades de exploração sexual, desde 2002, o trabalho da polícia segue focado na prostituição. $O$ mais interessante, nesse caso específico, é lembrar que a Colômbia legalizou a prostituição de adultas e fiscaliza essa atividade do ponto de vista da Saúde. Todas as trabalhadoras sexuais regulares devem ter cadastro no ministério.

Segundo especialistas de organismos internacionais entrevistados, notadamente do UNODC e da Organização Internacional para as Migrações (OIM), existem duas razões principais para essa situação. Em primeiro lugar, as questões culturais tratadas na abertura deste artigo. Em segundo, o fato do combate ao crime organizado, considerando o tráfico de pessoas como uma de suas áreas de atuação, exigir das instituições do Sistema de Justiça, a começar pela polícia, um alto investimento financeiro traduzido na valorização profissional dos operadores especializados no crime de tráfico de pessoas, bem como em gastos com equipamentos de rastreamento telefônico e softwares 
Sobre armadilhas e cascas de banana

para cruzamento de dados financeiros, por exemplo, além de um programa constante de capacitação e aperfeiçoamento. Mais uma vez a complexidade do próprio tráfico de pessoas e a maneira como opera demanda um tipo de qualificação e de gasto por parte do Estado que, até o momento, não foi feito.

Tomando como referência a Colômbia para falar do Brasil, precisamos ter clareza de que adequações normativas, por melhores que sejam do ponto de vista da técnica jurídica e legislativa, não provocam impacto na vida real das pessoas, sem um investimento consciente e sistemático do Estado para que as mudanças sejam incorporadas na cultura das instituições e, mais do que isso, para que existam condições reais para sua aplicação.

\section{Colocando o tema na agenda pública nacional}

Uma percepção reducionista do tráfico, que o confunde com a prostituição, cria uma série de barreiras a um debate mais amplo que articule as diferentes modalidades de exploração e, ao mesmo tempo, gere resistência em atores sociais fundamentais para a construção de uma política pública efetiva nesse tema, como é o caso das próprias prostitutas que, muitas vezes, se sentem ameaçadas pelas discussões sobre tráfico de pessoas.

A falta de uma definição acerca do status legal da prostituição no Brasil acaba virando o centro das discussões sobre tráfico de pessoas, muitas vezes, paralisando o debate público e a possibilidade de avanços no desenho de ações efetivas $e$ integradas. Nas discussões da Política Nacional de Enfrentamento ao Tráfico de Pessoas ${ }^{9}$, das quais fui uma das coordenadoras, um dos momentos mais difíceis ocorreu durante o seminário nacional, em Brasília, em 2006. Um dos grupos que debatia os princípios norteadores do documento percebeu que não existia nenhuma definição internacional sobre exploração, tampouco existe uma

9 Decreto presidencial de número 5.948, de 26/10/2006, pode ser encontrado no site www.mj.gov.br/segurancapublica/traficosereshumanos/publicações. 
posição consolidada no Brasil sobre o status legal que a prostituição deve ter. Alguns defenderam que não se poderia escrever uma política sobre tráfico de pessoas, sem antes desatar esses nós.

Embora tenhamos chegado ao final daquele processo, posteriormente, esbarramos com pesadas críticas das prostitutas organizadas que defendem que, sem clarear os termos do debate, qualquer discussão sobre tráfico de pessoas é prejudicial ao grupo dos que desejam ver a prostituição regulamentada como atividade profissional.

Sem a participação efetiva dos segmentos da sociedade diretamente ligados aos contextos nos quais o tráfico de pessoas acontece, a administração de Justiça no tema torna-se capenga. Isso porque em qualquer crime que envolva uma violação de Direitos Humanos, pelo menos em tese, a vítima deve ser a maior beneficiária da ação do Estado e o Sistema de Justiça tem um papel fundamental para garantir a reparação moral, mas também financeira, pelo dano sofrido. Seguindo essa lógica, a atuação da polícia como porta de entrada do Sistema de Justiça precisará, necessariamente, estar amparada por uma rede de organizações de retaguarda social capaz de prover serviços de assistência psicossocial e legal seja à vítima do trabalho escravo, do aliciamento para o trabalho ou do tráfico interno ou internacional de pessoas.

$\mathrm{Na}$ prática, ao tentar articular uma política nacional de enfrentamento ao tráfico de pessoas que integre prevenção, a responsabilização e a atenção à vítima, o primeiro desafio é aglutinar redes completamente diferenciadas de profissionais, de instituições e de movimentos sociais. Mais do que isso, trata-se de motivá-los a discutir não o trabalho escravo, tampouco a exploração sexual ou a migração irregular para o trabalho, mas algo muito específico desses universos maiores com os quais esses mesmos atores estão acostumados a lidar. É quase como convencê-los a focar dentro da sua área de atuação, geralmente muito mais ampla, em um segmento absolutamente diferenciado, 
Sobre armadilhas e cascas de banana

sem que passem a enxergar a ocorrência de tráfico em todos os lugares. Há uma linha muito tênue entre responder a um problema concretamente colocado $e$, no outro extremo, transformar em tráfico todo trabalho escravo, toda migração irregular para o trabalho ou toda situação de prostituição.

É inegável a tentação de agir em nome de uma boa causa que é chamar a atenção para uma violação gravíssima de Direitos Humanos e provocar um pânico generalizado. Entretanto, na realidade, esse tipo de atuação só prejudica os sujeitos que supostamente deveria proteger pelo cacoete do Estado de, em nome da proteção, querer controlar os sujeitos mais vulneráveis a esse problema (Ausserer, 2007).

Como estratégia de agendamento, a sobriedade exigida nesse campo dificulta o processo de convencimento de redes focadas nos contextos mais amplos, nos quais ocorrem casos de tráfico de pessoas, da importância e da pertinência política, financeira e social de dar prioridade a um problema recheado de especificidades que, muitas vezes, acaba sumindo ou escapando misturado com questões mais amplas de trabalho, de gênero, de migração, de exclusão social ou de saúde, entre outros.

Em diversas reuniões realizadas ao longo de minha experiência como gestora de política pública nessa área, ouvia sempre a mesma sugestão sobre como resolver o problema do tráfico de pessoas, vinda de interlocutores os mais diversos - do taxista, passando pelo jornalista, até o primeiro escalão de governo: é preciso impedir essas "moças" de deixarem o país. Depois de algum tempo, aprendi a devolver a sugestão com a seguinte pergunta: e depois, fazemos o que com elas? Ninguém me respondeu até hoje e nem eu mesma consigo arriscar uma resposta que seja completamente honesta, mas certamente é uma luta que vale a pena. 
Marina Pereira Pires de Oliveira

\section{Referências bibliográficas}

Agustin, Laura. Sex at the Margins, Migration, Labor Markets and the Rescue Industry. London/New York, Zed Books, 2007.

ANDERSON, Bridget \& O'CONNELl DAvidSON, Julia. Trafficking, a demand -led problem? A multy-country pilot study. Part 1 "Review of evidence and debates", Save the Children, 2004. http://www.jagori.org/ research_dst.htm.

AUSSERER, Caroline. Controle em nome da proteção: Análise crítica dos discursos sobre o tráfico internacional de pessoas. Dissertação de Mestrado, Relações Internacionais, PUC-RJ, 2007.

BARRY, Kathleen. Prostitution of sexuality: a cause for new international human rights. Journal of Loss and Trauma (2:1), 1997, pp.27-48.

FONSECA, Cláudia. A dupla carreira da mulher prostituta. Revista Estudos Feministas, n 1, 1996, pp.7-33.

PISCITELLI, Adriana. Sujeição ou subversão? Migrantes brasileiras na indústria do sexo na Espanha. Histórias e Perspectivas (35), Universidade Federal de Uberlândia/UFU, 2006(a).

Antropologia, direitos humanos e o debate sobre tráfico de pessoas com fins de exploração sexual. Anais da $25^{a}$ Reunião da Associação Brasileira de Antropologia, Goiânia, CD, 2006 (b). 